SATIN - Sains dan Teknologi Informasi

\title{
Game Edukasi Marbel Tajwid
}

\author{
Ahmad Zaky Yamani \\ Sistem Informasi \\ STMIK Nusa Mandiri \\ ahmadzakyyamani01@gmail.com
}

\author{
Cep Adiwihardja \\ Teknologi Komputer \\ Universitas Bina Sarana \\ Informatika \\ cep.caw@bsi.ac.id
}

\author{
Nicodias Palasara \\ Sistem Informasi \\ STMIK Nusa Mandiri \\ nico.ncp@nusamandiri.ac.id
}

\begin{abstract}
Most Muslims have difficulty memorizing various types of Tajweed knowledge. One solution is at TPQ (Taman Pendidikan Quran) Assa'adah. However, limited learning causes children to be bored, mainly, it reduces children's interest in learning. Nowadays, by the existence of the innovation and technological development, interactive educational games are made, of course it contains text, graphics or images, supporting animated images, audio, music. It is able to arise fun and enthusiasm in the learning process. So that, children's motivation to learn will be increasing automatically and it will not show the sense of boredom. Certainly, it is expected that learning objectives will be more optimal. In making this educational game, the writer uses the method of Waterfall. So that, the stages are easier to understand and the logic development model can be understood by the flow system. This educational game aims to help the learning process in reading the Qur'an that is good and right (tartil). The results of this interactive animation media applied to learn Tajweed become easy and fun because it is designed with a colorful display.
\end{abstract} Game

Key Words : Education, Marbel, Tajweed, Waterfall,

\begin{abstract}
Abstrak
Sebagian besar umat muslim kesulitan dalam menghafal berbagai macam jenis ilmu tajwid. Salah satu tempat belajar ilmu tajwid adalah di TPQ Assa'adah. Namun pembelajaran yang terbatas menyebabkan anak menjadi bosan sehingga mengurangi ketertarikan anak pada pelajaran. Dengan inovasi dan perkembangan teknologi maka dibuatkannya animasi interaktif game edukasi yang berisi antara teks, grafik atau gambar, animasi gambar yang mendukung, audio, musik, mampu menimbulkan rasa senang dan semangat dalam proses belajar. Sehingga motivasi belajar anak akan bertambah dan tidak menimbulkan rasa jenuh dan dengan ini diharapkan tujuan pembelajaran menjadi lebih maksimal. Dalam pembuatan game edukasi ini peneliti menggunakan metode waterfall sehingga dalam tahapannya lebih mudah dimengerti dan model pengembangan logikanya dapat dipahami sistem alur berjalannya. Game edukasi ini bertujuan untuk membantu proses pembelajaran dalam pembacaan alqur'an yang baik dan benar (tartil). Hasil dari diterapkan media animasi interaktif ini belajar tajwid menjadi mudah dan menyenangkan karena didesain dengan dengan tampilan penuh warna.
\end{abstract}

Kata Kunci : Edukasi, Marbel, Tajwid, Waterfall, Permainan 


\section{Pendahuluan}

Membaca Al-Qur'an yang baik dan benar(tartil) agar sesuai dengan aturan membacanya yang dikenal dengan nama ilmu tajwid yang merupakan suatu kewajiban bagi setiap muslim. Ilmu tajwid merupakan ilmu yang digunakan untuk memperelok dan memperdalam pembacaan Al-Qur'an, jelas, terarah dan detail serta pembacaan Al-Qur'an tidak asal kencang akan tetapi sesuai dengan kaidahnya.

Pembelajaran agama islam di TPQ sangat efektif dikarenakan waktu mengajar dikhususkan untuk belajar agama islam saja, akan tetapi minat belajar anak-anak perlu ditingkatkan, karena metode pembelajaran masih menggunakan cara konvensional. Metode konvensional yaitu pengajar memberikan materi hanya dari buku dan belum menambahkan media teknologi dalam pengajaran secara maksimal.

Untuk meningkat minat anak perlu dibuatkan belajar tajwid dengan animasi yang atraktif, sehingga aplikasi yang akan dibuat dimana game edukasi marbel tajwid. Yang diharpakan dapat meningkatkan minat belajar anak-anak.

Menurut (Haryanto \& Adiwiharja, 2015) "Penerapan media pembelajaran berbasis multimedia melalu permainan akan sangat menarik antusiasme siswa. Dengan memasukan materi pelajaran kedalam permainan, dapat mendorong siswa untuk belajar secara aktif dan menyenangkan tanpa rasa jenuh"

Menurut (Al-Qudhat, 2015) mengatakan bahwa "Ilmu tajwid adalah ilmu yang mempelajari bagaimana menempatkan huruf pada tempatnya".

Membaca Al-Qur'an yang baik dan benar(tartil) agar sesuai dengan aturan membacanya yang dikenal dengan nama ilmu tajwid yang merupakan suatu kewajiban bagi setiap muslim. Ilmu tajwid merupakan ilmu yang digunakan untuk memperelok dan memperdalam pembacaan Al-Qur'an, jelas, terarah dan detail serta pembacaan Al-Qur'an tidak asal kencang akan tetapi sesuai dengan kaidahnya. Lazimnya membaca Al-Qur'an tidak hanya membaca, karena membaca Al-Qur'an berbeda dengan membaca teks arab (Abidin \& Listyorini, 2018).

Menurut (Maarif, Nur, \& Rahayu, 2018) menyatakan bahwa, "Sebagian besar umat muslim mengalami kesulitan dalam menghafal berbagai macam jenis ilmu tajwid dan menerapkannya saat membaca AlQur'an".

Taman pendidikan Al-Qur'an atau disebut juga TPQ merupakan pendidikan non formal jenis keagamaan, materi utamanya adalah kitab suci Al-Qur'an. Tujuannya adalah untuk memberikan pengajaran membaca Al-Qur'an, menanamkan nilai moral dan etika bagi anak-anak (Rini, Pramana, \& Ridwan, 2017).

Pembelajaran agama islam di TPQ sangat efektif dikarenakan waktu mengajar dikhususkan untuk belajar agama islam saja, akan tetapi minat belajar anak-anak menjadi menurun, karena metode pembelajaran masih menggunkan cara konvensional yaitu pengajar memberikan materi hanya dari buku dan belum menambahkan media teknologi dalam pengajaran secara maksimal.

\section{Landasan Teori}

Pada bagian ini dipaparkan teori-teori serta pustaka yang dipakai pada penelitian ini.

\subsection{Konsep Dasar Program}

Menurut (Saragih, 2018) mengatakan bahwa, "Program adalah sebuah elemen inti untuk kinerja suatu perangkat. Program inilah yang akan memproses perintah yang diberikan oleh user agar dapat dikelola oleh perangkat/device".

\subsection{Animasi}

Menurut (Surjono, 2017) menyatakan bahwa, "Animasi adalah rangkaian gambar yang bergerak secara urut guna menyajikan suatu proses tertentu. Animasi merupakan salah satu komponen multimedia yang menarik dan banyak digunakan untuk menyajikan materi pembelajaran yang sulit".

\subsection{Multimedia}

Menurut (Arifin, Ricky, \& Yesmaya, 2015) Multimedia adalah kombinasi berbagai sarana baik berupa teks, gambar suara, animasi maupun vidio untuk menampilkan atau sebagai medium untuk mendistribusikan informasi dalam berbagai bentuk melalui peralatan digital meliputi komputer, tablet, smartphone, dan PDA.

Menurut (Nurjayadi dan andesa, 2014) bahwa "multimedia merupakan kombinasi dari komputer dan video, sedangkan multimedia itu sendiri tidak tergantung dari komputer saja, bisa mencakup dari handphone, televisi, kamera, dan alat elektronik, dan media apa saja, yang bisa dibuat pertunjukan"

\subsection{CorelDraw}

Menurut (andi \& madcoms, 2015) mengatakan bahwa, "CorelDraw adalah suatu aplikasi desain grafis yang digunakan untuk membuat desain vector seperti: Logo, layout, visual, dan desain advertising".

\subsection{Pengujian White Box}


Menurut (Sukamto \& Shalahuddin, 2015) mengatakan bahwa, "menguji perangkat lunak dari segi desain dan kode program apakah mampu menghasilkan fungsi-fungsi, masukan, dan keluaran yang sesuai dengan spesifikasi kebutuhan”.

\subsection{Pengujian Black Box}

Pengujian Black Box testing menurut (Sukamto \& Shalahuddin, 2015) mengatakan bahwa, "menguji perangkat lunak dari segi spesifikasi fungsional tanpa menguji desain dan kode program. Pengujian dimaksudkan untuk mengetahui apakah fungsi-fungsi masukan, dan keluaran dari perangkat lunak sesuai dengan spesifikasi yang dibutuhkan".

\subsection{Antar Muka}

Menurut (Karpen, 2012) bahwa "rancangan antarmuka sebagai media komunikasi untuk manusia dan mesin, diharapkan adanya sistem komputer yang dapat mempunyai sifat yang akrab dan ramah dengan pengguna (user)".

\subsection{Storyboard}

Menurut (Surjono, 2017) mengatakan bahwa, "storyboard adalah rancangan segala sesuatu yang akan ditampilkan dilayar dan merupakan skenario dalam bentuk visual". Storyboard merupakan Serangkaian gambaran pertama untuk menciptakan aplikasi game sesuai dengan jalan cerita yang ditentukan.

\section{Metode Penelitian}

Metode penelitian adalah bagaimana seorang peneliti dapat memahami suatu pembahasan, permasalahan, dan pemecahan suatu masalah.

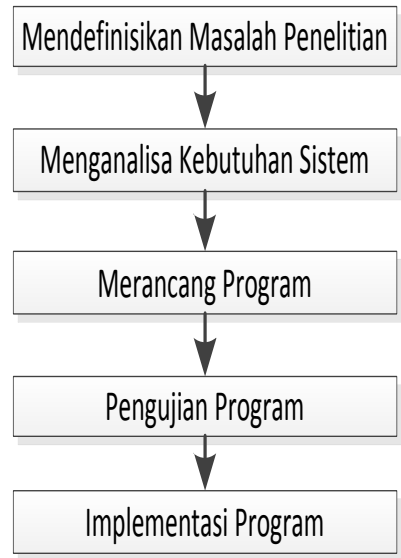

Gambar 1. Langkah Penelitian

\section{a. Mendefinisikan Masalah Penelitian}

Pada tahap ini mencari masalah yang ada untuk dapat dibuatkan sebuah program yang dapat berjalan sesuai dengan yang diharapkan.

b. Menganalisa Kebutuhan Sistem

Mengklarifikasi beberapa perangkat yang digunakan untuk membuat aplikasi perangkat lunak.

c. Merancang Program

Membuat desain rancangan program yang dibuat dengan storyboard dan white box.

\section{d. Pengujian Program}

Ditahap ini setalah rancangan sudah dibuatkan, lalu diterapkan dan diuji menggunakan black box testing.

\section{e. Impementasi Program}

Lalu diterapkan ke user dalam bentuk game edukasi marbel Tajwid

\subsection{Teknik pengumpulan data}

Metode pengumpulan data yang peneliti gunakan yaitu :

1. Observasi yaitu melakukan pengamatan, pencatatan dan pengumpulan data secara langsung di TPQ Assa'adah, dengan mengamati proses cara belajar mengajar tajwid.

2. Wawancara yaitu pengumpulan informasi secara lengkap dengan melakukan wawancara langsung pada salah satu guru yang mengajar di TPQ Assa'adah, dengan menanyakan proses belajar mengajar, apa yang membuat anak sulit untuk belajar tajwid dan apa yang dibutuhkan dalam proses belajar mengajar.

3. Studi Pustaka yaitu peneliti melakukan kegiatan mengumpulkan informasi atau referensi mengenai topik terkait melalui bukubuku, jurnal-jurnal, e-book dan internet.

\subsection{Model Pengembangan Sistem}

Model Pengembangan sistem yang peneliti gunakan adalah model SDLC (Waterfall) (Sukamto \& Shalahuddin, 2015), yang terdiri dari :

1. Analisa Kebutuhan Sistem

2. Desain

3. Code Generation

4. Testing

5. Support

Model ini sangat cocok diterapkan karena sistem model waterfall sangat terurut dimulai dari awal, proses, sampai dengan selesai serta diakhiri pengujian sebelum 
digunakan ke user lain. Kelemahan dari model ini adalah lama dalam pengerjaannya, dikarenakan model ini terurut satu persatu, apabila dalam tahap-tahapnya belum selesai maka belum bisa ketahap selanjutnya.

\section{Hasil dan Pembahasan}

Berikut adalah hasil dan pembahasan mengenai game edukasi marbel tajwid pada TPQ Assa'adah.

\subsection{Analisa Kebutuhan Sistem}

Pada tahap ini peneliti mengklarifikasi beberapa perangkat yang digunakan untuk membuat aplikasi perangkat lunak. Berikut adalah spesifikasi yang peneliti gunakan.

1. Spesifikasi Software

Perangkat lunak yang digunakan untuk membuat program aplikasi game edukasi belajar tajwid adalah sebagai berikut:

a. Sistem Operasi Windows 10 64-bit.

b. Construct 2.

c. Corel Draw X7.

d. Dia.

e. Format Factory.

f. Phonegap.

2. Spesifikasi hardware

Perangkat keras yang dibutuhkan untuk dapat membuat dan menjalankan aplikasi ini adalah Personal Computer (PC) atau laptop dengan spesifikasi sebagai berikut :
a. Processor : Intel Core i3
b. RAM :6 GB
c. Monitor : 16 Inch
d. Speaker : Polytron

\subsection{Desain}

\subsubsection{Perancangan Storyboard}

Perancangan storyboard membahas alur cerita dari aplikasi yang dibuat yang disampaikan menggunakan tulisan dan gambar sketsa. Berikut adalah storyboard perancangan game edukasi marbel tajwid yang dibuat.

Tabel 1. Storyboard menu utama

\begin{tabular}{|c|c|c|}
\hline Visual & Sketsa & Audio \\
\hline \multirow{5}{*}{$\begin{array}{lr}\text { Pada } & \text { tampilan } \\
\text { menu } & \text { utama } \\
\text { terdapat } & \text { tombol } \\
\text { menu } & \text { belajar } \\
\text { tajwid, tombol } & \text { tombra } \\
\text { bermain, tombol } \\
\text { info, tombol menu } \\
\text { bantuan, tombol } \\
\text { musik, tombol } \\
\text { efek, karakter, dan } \\
\text { tombol keluar. }\end{array}$} & 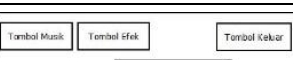 & \multirow{5}{*}{$\begin{array}{l}\text { Musik1.ogg } \\
\text { Klik.ogg } \\
\text { Marbel.ogg } \\
\text { Play Games.ogg } \\
\text { charactermu.ogg. }\end{array}$} \\
\hline &  & \\
\hline & 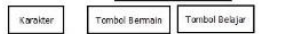 & \\
\hline & Tantolinto & \\
\hline & & \\
\hline
\end{tabular}



4.2.2. User Interface

User Interface adalah gambaran suatu perancangan tampilan antar muka animasi interaktif game edukasi marbel tajwid.

a. Tampilan interface menu bermain

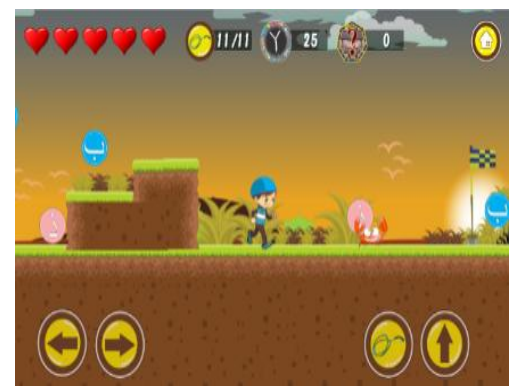

Gambar 2. Tampilan menu bermain

Pada scane ini pemain ditugaskan untuk mengumpulkan koin hijaiyah dan menjawab soal yang ada didalam koin sesuai dengan misi masing-masing. Didalam nya terdapat 4 tombol yaitu :

1. Tombol "Kanan" berfungsi untuk mengubah gerak player ke kanan.

2. Tombol "Kiri" berfungssi untuk mengubah gerak player ke kiri.

3. Tombol "Atas" berfungsi untuk membuat player melompat. 
4. Tombol "Peluru" berfungsi untuk melemparkan peluru untuk membunuh musuh.

5. Tombol "Keluar" untuk membuka opsi pilihan tombol, jika ditekan tombol "YA" maka akan kembali ke menu utama, jika "TIDAK" maka akan melanjutkan kembali permainan.

\subsubsection{State Transition Diagram}

State transition diagram adalah diagram yang menggambarkan bagaimana suatu proses terhubung satu dengan yang lainnya dalam waktu yang bersamaan (Real Time System).

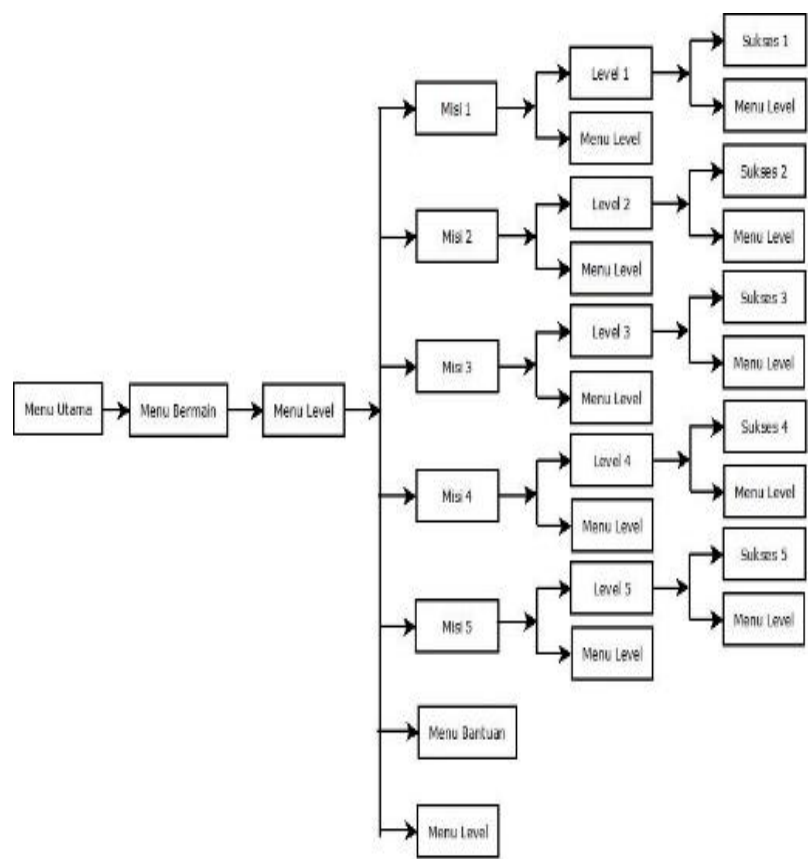

Gambar 3. State transition diagram menu utama

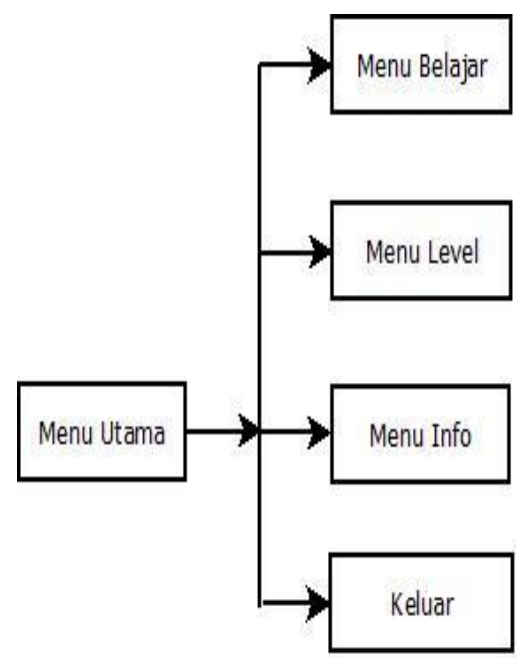

Gambar 4. State transition diagram menu belajar

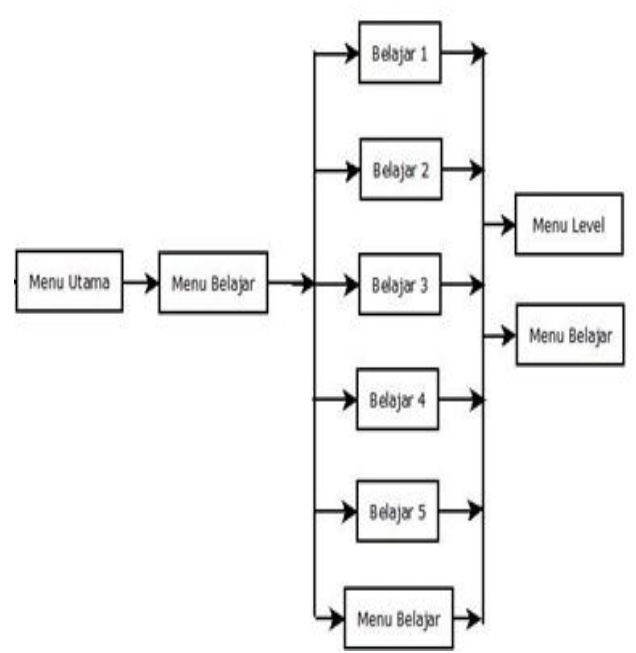

Gambar 5. State transition diagram menu bermain

\subsubsection{White Box}

Metode ini menggunakan struktur control desain procedural (structure testing) untuk memperoleh test case. Fungsi pengujian ini untuk memastikan semua statement pada program telah dieksekusi setidaknya satu kali selama pengujian dan semua kondisi logis telah diuji. Metode ini meengggunakan pengukuran kuantitatif terhadap kompleksitas logis suatu program (kompleksitas siklomatis) diproleh dari perhitungan dengan rumus sebagai berikut :

$\mathrm{V}(\mathrm{G})=\mathrm{E}-\mathrm{N}+2$

Keterangan :

$\mathrm{E}=$ Jumlah egde grafik alir yang ditandakan dengan tanda panah

$\mathrm{N}=$ Jumlah simpul grafik alir yang ditandakan dengan gambar lingkaran.

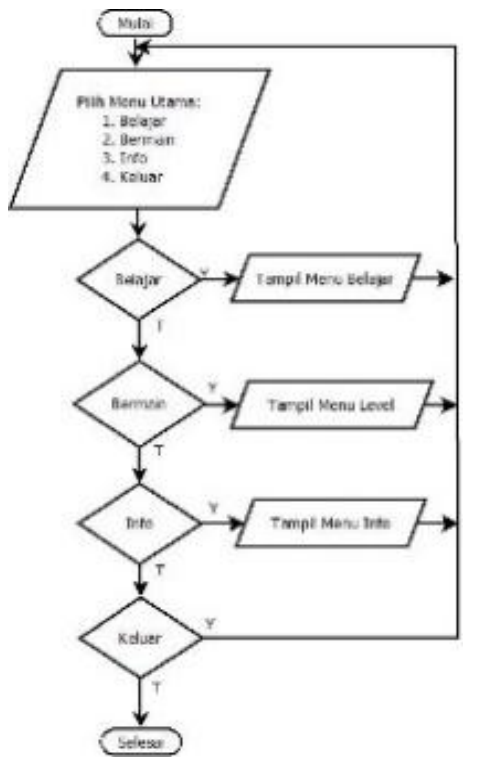

Gambar 6. Bagan Alir Menu Utama 
Kompleksitas siklomatis (Pengukuran kuantitatif terhadap kompleksitas logis suatu program) dari grafik alir dapat diperoleh dengan perhitungan sebagai berikut:

$$
\begin{aligned}
\mathrm{V}(\mathrm{G}) & =\mathrm{E}-\mathrm{N}+2 \\
& =13-10+2 \\
& =5
\end{aligned}
$$

Basis set yang dihasilkan dari bagan grafik alir menu opening sebagai berikut :

Path 1 : 1-2-3-8-2

Path 2 : 1-2-3-4-9-2

Path 3 : 1-2-3-4-5-10-2

Path $4: 1-2-3-4-5-6-2$

Path 5 : 1-2-3-4-5-6-7

Ketika aplikasi dijalankan, maka akan terlihat bahwa salah satu basis set yang dihasilkan adalah 1-23-4-5-6-7 dan terlihat bahwa simpul telah dieksekusi satu kali.

Berdasarkan pengamatan dan ketentuan tersebut dari segi kelayakan perangkat lunak, system ini telah memenuhi syarat.

\subsubsection{Black Box}

Pengujian ini dilakukan untuk memastikan bahwa suatu event atau masukan akan menjalankan proses yang tepat dan menghasilkan output sesuai

\begin{tabular}{|c|c|c|c|}
\hline $\begin{array}{l}\text { Input/ } \\
\text { Event }\end{array}$ & Proses & $\begin{array}{c}\text { Output/ } \\
\text { Next Stage }\end{array}$ & $\begin{array}{c}\text { Hasil } \\
\text { Pengujia } \\
\mathbf{n}\end{array}$ \\
\hline $\begin{array}{l}\text { Tombol } \\
\text { Belajar }\end{array}$ & $\begin{array}{l}\text { <actions> } \\
<\text { action id="-2" } \\
\text { name="Go to } \\
\text { layout" } \\
\text { sid="7728144022 } \\
523872 " \\
\text { type="System"> } \\
\text { l<param id="0" } \\
\text { name="Layout"> } \\
\text { Menu Pilih } \\
\text { Belajar</param> } \\
</ \text { action> }\end{array}$ & $\begin{array}{l}\text { Menampilk } \\
\text { an halaman } \\
\text { Pilih Materi } \\
\text { Pembelajara } \\
\text { n }\end{array}$ & Sesuai \\
\hline $\begin{array}{l}\text { Tombol } \\
\text { Bermai } \\
\mathrm{n}\end{array}$ & $\begin{array}{l}<\text { action id="-2" } \\
\text { name="Go to } \\
\text { layout" } \\
\text { sid="1707685199 } \\
07408 " \\
\text { type="System"> } \\
\text { <param id="0" } \\
\text { name="Layout"> } \\
\text { Menu } \\
\text { Level</param> } \\
</ \text { action> }\end{array}$ & $\begin{array}{l}\text { Menampilk } \\
\text { an halaman } \\
\text { menu level }\end{array}$ & Sesuai \\
\hline
\end{tabular}
dengan rancangan yang dibuat.

\begin{tabular}{|c|c|c|c|}
\hline $\begin{array}{l}\text { Tombol } \\
\text { Info }\end{array}$ & $\begin{array}{l}\text { <action id="-2" } \\
\text { name="Go to } \\
\text { layout" } \\
\text { sid="9390366642 } \\
16554 " \\
\text { type="System"> } \\
<\text { param id="0" } \\
\text { name="Layout"> } \\
\text { Menu } \\
\text { Info</param> } \\
</ \text { action> }\end{array}$ & $\begin{array}{l}\text { Menampilk } \\
\text { an halaman } \\
\text { info }\end{array}$ & Sesuai \\
\hline $\begin{array}{l}\text { Tombol } \\
\text { Keluar }\end{array}$ & 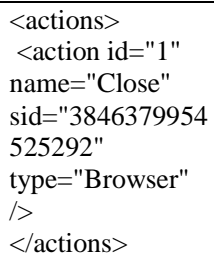 & $\begin{array}{l}\text { Keluar/Tutu } \\
\text { p aplikasi }\end{array}$ & Sesuai \\
\hline
\end{tabular}

Tabel 2. Pengujian unit blackbox testing

\subsubsection{Hasil pengolahan data kuesioner game edukasi}

Berikut adalah rincian dari pertanyaan yang ada dikuesioner untuk murid TPQ assa'adah:

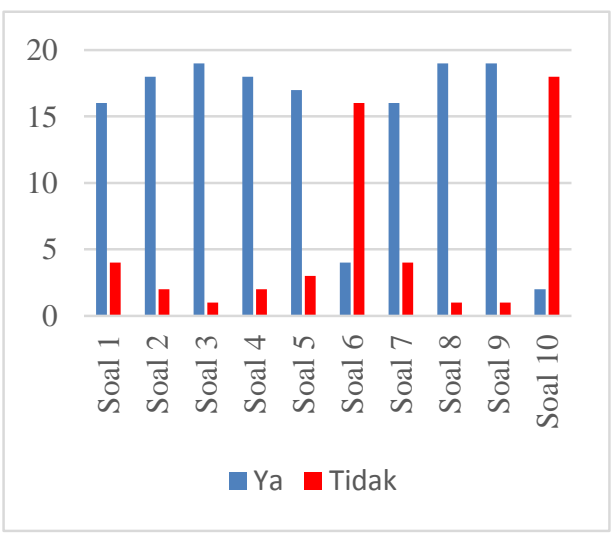

Gambar 7. Tampilan grafik kuesioner murid tpq assa'adah

Tabel 3. Hasil Pengolahan Kuesioner

\begin{tabular}{|c|c|}
\hline Ya & Tidak \\
\hline 16 & 4 \\
\hline 18 & 2 \\
\hline 19 & 1 \\
\hline 18 & 2 \\
\hline 17 & 3 \\
\hline 4 & 16 \\
\hline 16 & 4 \\
\hline
\end{tabular}




\begin{tabular}{|c|c|}
\hline 19 & 1 \\
\hline 19 & 1 \\
\hline 2 & 18 \\
\hline
\end{tabular}

Sumber : Hasil Pengolahan Data (2019)

Dari hasil Kuesioner pada tabel diatas dapat diambil kesimpulan bahwa sebagian besar murid dapat menggunakan aplikasi ini dengan mudah karena bahasa yang mudah dimengerti dan suara yang jelas, serta memudahkan dalam mempelajari ilmu tajwid, dan belajar tajwid menjadi menyenangkan karena didesain dengan tampilan fullcolor.

\section{Simpulan}

Simpulan yang peneliti dapatkan setelah melakukan penelitian ini, adalah :

1. Dengan adanya aplikasi ini menjadi alternatif untuk mempelajari ilmu tajwid.

2. Dengan dibuatnya aplikasi ini, maka metode pembelajaran ilmu tajwid menjadi lebih menyenangkan, serta tidak terbatas oleh waktu untuk belajar. 3. Game edukasi ini mudah dipahami karena dirancang dengan tampilan menarik, edukatif, sehingga tidak membuat murid TPQ Assa'adah tidak cepat bosan dalam mempelajari ilmu tajwid.

\section{Referensi}

Abidin, M. Z., \& Listyorini, T. (2018). Game Edukatif Membaca Al-Qur'an (Ilmu Tajwid) Berbasis Android. SINTECH (Science and Information Technology) Journal, 1(1), 1-6. https://doi.org/10.31598/sintechjournal.v1i1.153

Andi, \& madcoms. (2015). Pasti Bisa !! Belajar Sendiri CorelDraw X7 (Cetakan 1). Retrieved from http://onesearch.id/Record/IOS5876.INLIS00000 0000021140\#description

Arifin, Y., Ricky, M. Y., \& Yesmaya, V. (2015). Digital MultimediA (1st ed.; Ariyanto, ed.). Jakarta Barat: Bina Nusantara Media \& Publishing.

Firly, N. (2018). Create Your Own Android Application. Retrieved from https://books.google.co.id/books?id=4LBfDwAA QBAJ

Haryanto, F. D., \& Adiwiharja, C. (2015). Media Pembelajaran Dengan. Jurnal Teknik Komputer Amik Bsi, I(2), 266-274.

Karpen (2012). Antarmuka Sebagai Media Komunikasi Dengan Sistem. Jurnal Sains dan Teknologi Informasi, 106-110.

Maarif, V., Nur, H. M., \& Rahayu, W. (2018). Aplikasi Pembelajaran Ilmu Tajwid Berbasis Android.
Evolusi, 6(1), 91-100.

Nurjayadi, \& Andesa, K., (2014). Implementasi Multimedia Interaktif Test Of English For International Communication ( TOEIC ). Jurnal Sains dan Teknologi Informasi, 12-15.

Rini, E. S., Pramana, D., \& Ridwan, E. (2017). Pemanfaatan Teknologi Informasi sebagai Upaya Peningkatan Pelayanan dalam Pengelolaan Taman Pendidikan di Bali. Seminar Nasional Teknologi Informasi Dan Multimedia, 5(1), 1218. Retrieved from http://ojs.amikom.ac.id/index.php/semnasteknom edia/article/view/1589

Saragih, R. R. (2018). Pemrograman dan Bahasa Pemrograman.

Scirra. (2019). Construct 2. Retrieved June 21, 2019, from https://www.scirra.com/construct2

Sukamto, R. A., \& Shalahuddin, M. (2015). Rekayasa Perangkat Lunak. In Informatika Bandung (3rd ed.). Bandung.

Surjono, H. D. (2017). Multimedia Pembelajaran Interaktif Konsep dan Pengembangan (pertama; U. Press, Ed.). Yogyakarta. 